\title{
Lipid Droplets: Their Role in Nanoparticle-Induced Oxidative Stress
}

\author{
Armen Khatchadourian and Dusica Maysinger* \\ Department of Pharmacology and Therapeutics, McGill University, 3655 Promenade Sir \\ William Osler, Montreal, Quebec, Canada H3G 1 Y6
}

Received January 7, 2009; Revised Manuscript Received May 12, 2009; Accepted May 15, 2009

\begin{abstract}
Lipid droplets are cytoplasmic organelles found in almost all cells under physiological or pathological conditions. Certain nanoparticles can induce lipid droplet formation under oxidative stress conditions. Small metallic nanoparticles such as cadmium telluride (CdTe) nanoparticles, particularly those with incompletely protected surfaces, induce oxidative stress and may inflict damages to several intracellular organelles. The objective of this study was to assess formation of lipid droplets in cells treated with CdTe nanoparticles and relate their status to cell function (mitochondrial activity and cell viability). Multicolor labeling of cellular organelles (lipid droplets and lysosomes) showed that lipid droplets formed in pheochromocytoma (PC12) cells following nanoparticle or oleic acid treatment. Some lipid droplets were found closely apposed to lysosomes suggesting possible communication between these organelles during severe oxidative stress. Combination of microscopy of living cells with cell viability assays showed that oleic acid-induced lipid droplets not only serve as intracellular lipid storage sites but also play a protective role in starving stressed cells. Results from these studies suggest that oleic acid-induced LD in PC12 cells are dynamic and adaptive organelles, which provide energy to starving cells and facilitate their rescue under starvation and exposure to metallic nanoparticles.
\end{abstract}

Keywords: Lipid droplets (LD); oxidative stress; nanoparticle; oleic acid; Bodipy 493/503; lysosome

\section{Introduction}

Lipid droplets (LDs) are cytoplasmic organelles found in most cell types, but their number and sizes vary from one cell type to the other. They consist of two major compartments: a core filled with neutral lipids, such as triacylglycerides (TG), diacylglycerol and cholesterol esters, and a surrounding phospholipid monolayer, which contains free cholesterol and proteins. ${ }^{1}$ During periods of nutrient shortage, lipolysis causes free fatty acids to be released from the TG stored in $\mathrm{LD}^{2-4}$ Although adipocytes are the cells specialized in lipolysis, all tissues must be able to convert their TG

* Corresponding author: Dr. Dusica Maysinger, McGill University, Pharmacology and Therapeutics, 3655 Promenade Sir William Osler, Montreal, Quebec, Canada H3G 1Y6. Tel: (514) 3981264 or (514) 398-4400 (ext 0838). Fax: (514) 398-6690. E-mail: dusica.maysinger@mcgill.ca.

(1) Murphy, D. J. The biogenesis and functions of lipid bodies in animals, plants and microorganisms. Prog. Lipid Res. 2001, 40 (5), 325-438. sources to free fatty acids during starvation periods. Initially, LDs have been regarded as static organelles mainly involved in fat storage, but more recently they were proposed to be dynamic bodies interacting with other cellular compartments. Recently, Goodman and Murphy reviewed different roles of LD and their dynamic interactions with several organelles. ${ }^{5,6}$

(2) Ducharme, N. A.; Bickel, P. E. Lipid droplets in lipogenesis and lipolysis. Endocrinology 2008, 149 (3), 942-9.

(3) Schmitz, G.; Grandl, M. Endolysosomal phospholipidosis and cytosolic lipid droplet storage and release in macrophages. Biochim. Biophys. Acta 2008. DOI: 10.1016/j.bbalip.2008.12.007.

(4) Smirnova, E.; Goldberg, E. B.; Makarova, K. S.; Lin, L.; Brown, W. J.; Jackson, C. L. ATGL has a key role in lipid droplet/ adiposome degradation in mammalian cells. EMBO Rep. 2006, 7 (1), 106-13.

(5) Goodman, J. M. The gregarious lipid droplet. J. Biol. Chem. 2008, 283 (42), 28005-9.

(6) Murphy, S.; Martin, S.; Parton, R. G. Lipid droplet-organelle interactions; sharing the fats. Biochim. Biophys. Acta 2008. DOI: 10.1016/j.bbalip.2008.07.004.

VOL. 6, NO. 4, 1125-1137 MOLECULAR PHARMACEUTICS 1125 
LDs are highly motile organelles and undergo microtubuledependent bidirectional movements in the cytoplasm. ${ }^{7}$ Their communication with other cellular compartments is supported by the presence of many membrane traffic regulating proteins, such as Rab and ARF1 (ADP-ribosylation factor), on their surfaces. ${ }^{5}$ Close apposition between LDs and organelles such as the mitochondria, peroxisomes and the endoplasmic reticulum (ER) have been detected by fluorescence resonance energy transfer (FRET) analysis and confocal and electron microscopy. ${ }^{8-10}$ However, studies employing multiple labeling of LD and other organelles using organelle-specific fluorescent dyes are rare.

In this study, we used organelle-specific dyes to investigate the status and the role of both LDs and lysosomes under nanoparticle-induced oxidative stress conditions and trophic factor deprivation in live PC12 cells. These are a wellestablished cell line in neuroscience, and they have been used for studying cytotoxicity of different nanoparticles. ${ }^{11}$ Recent studies suggest that metallic nanoparticles containing cadmium, tellurium or mercury can induce oxidative stress. ${ }^{11-18}$ It was proposed that enhanced formation of LDs could be a common cellular response to stress inducing nanomaterials. ${ }^{15,16}$

(7) Valetti, C.; Wetzel, D. M.; Schrader, M.; Hasbani, M. J.; Gill, S. R.; Kreis, T. E.; Schroer, T. A. Role of dynactin in endocytic traffic: effects of dynamitin overexpression and colocalization with CLIP-170. Mol. Biol. Cell 1999, 10 (12), 4107-20.

(8) Binns, D.; Januszewski, T.; Chen, Y.; Hill, J.; Markin, V. S.; Zhao, Y.; Gilpin, C.; Chapman, K. D.; Anderson, R. G.; Goodman, J. M. An intimate collaboration between peroxisomes and lipid bodies. J. Cell Biol. 2006, 173 (5), 719-31.

(9) Sturmey, R. G.; O’Toole, P. J.; Leese, H. J. Fluorescence resonance energy transfer analysis of mitochondrial:lipid association in the porcine oocyte. Reproduction 2006, 132 (6), 829-37.

(10) Ozeki, S.; Cheng, J.; Tauchi-Sato, K.; Hatano, N.; Taniguchi, H.; Fujimoto, T. Rab18 localizes to lipid droplets and induces their close apposition to the endoplasmic reticulum-derived membrane. J. Cell Sci. 2005, 118 (Part 12), 2601-11.

(11) Lovric, J.; Bazzi, H. S.; Cuie, Y.; Fortin, G. R.; Winnik, F. M.; Maysinger, D. Differences in subcellular distribution and toxicity of green and red emitting CdTe quantum dots. J. Mol. Med. 2005, 83 (5), 377-85.

(12) Cho, S. J.; Maysinger, D.; Jain, M.; Roder, B.; Hackbarth, S.; Winnik, F. M. Long-term exposure to CdTe quantum dots causes functional impairments in live cells. Langmuir 2007, 23 (4), 197480.

(13) Choi, A. O.; Cho, S. J.; Desbarats, J.; Lovric, J.; Maysinger, D. Quantum dot-induced cell death involves Fas upregulation and lipid peroxidation in human neuroblastoma cells. J. Nanobiotechnol. 2007, 5, 1 .

(14) Lovric, J.; Cho, S. J.; Winnik, F. M.; Maysinger, D. Unmodified cadmium telluride quantum dots induce reactive oxygen species formation leading to multiple organelle damage and cell death. Chem. Biol. 2005, 12 (11), 1227-34.

(15) Maysinger, D. Nanoparticles and cells: good companions and doomed partnerships. Org. Biomol. Chem. 2007, 5 (15), 233542.

(16) Seleverstov, O.; Zabirnyk, O.; Zscharnack, M.; Bulavina, L.; Nowicki, M.; Heinrich, J. M.; Yezhelyev, M.; Emmrich, F.; O'Regan, R.; Bader, A. Quantum dots for human mesenchymal stem cells labeling. A size-dependent autophagy activation. Nano Lett. 2006, 6 (12), 2826-32.
With growing production of different nanomaterials including nanoparticles and their possible slipping cell security, it is of interest to explore nanoparticle interactions with different organelles and relate them to changes in cellular functions. ${ }^{19-21}$ It is of particular interest to investigate consequences of longterm exposure of cells to hardly detectable nanoparticles since their insult to individual cellular organelles could lead to irreversible untoward changes to cellular organelles and eventually cell death. ${ }^{12,13,22}$ We used PC12 cells to examine a possible role of $\mathrm{LD}$ formation in the presence and absence of nanoparticles and also with and without monounsaturated fatty acid, oleic acid. LD formation is commonly induced by long-chain unsaturated fatty acids such oleic acid $(\mathrm{C} 18: 1) .{ }^{23,24}$ We selected oleic acid because it is a major component of the plasma and is commonly used to induce LDs in different cell types without causing cytotoxicity when applied within a physiological concentration range. ${ }^{24-27}$

Fluorescence-based detection of LDs is commonly achieved in fixed cells with oil-red-O (ORO) and in live cells with

(17) Stern, S. T.; Zolnik, B. S.; McLeland, C. B.; Clogston, J.; Zheng, J.; McNeil, S. E. Induction of Autophagy in Porcine Kidney Cells by Quantum Dots: A Common Cellular Response to Nanomaterials? Toxicol. Sci. 2008, 106 (1), 140-52.

(18) Zabirnyk, O.; Yezhelyev, M.; Seleverstov, O. Nanoparticles as a novel class of autophagy activators. Autophagy 2007, 3 (3), 27881.

(19) Xia, Y. Nanomaterials at work in biomedical research. Nat. Mater. 2008, 7 (10), 758-60.

(20) Verma, A.; Uzun, O.; Hu, Y.; Hu, Y.; Han, H. S.; Watson, N.; Chen, S.; Irvine, D. J.; Stellacci, F. Surface-structure-regulated cell-membrane penetration by monolayer-protected nanoparticles. Nat. Mater. 2008, 7 (7), 588-95.

(21) Hardman, R. A toxicologic review of quantum dots: toxicity depends on physicochemical and environmental factors. Environ. Health Perspect. 2006, 114 (2), 165-72.

(22) Maysinger, D.; Lovric, J. Quantum dots and other fluorescent nanoparticles: quo vadis in the cell. Adv. Exp. Med. Biol. 2007, 620, 156-67.

(23) Yonezawa, T.; Yonekura, S.; Kobayashi, Y.; Hagino, A.; Katoh, K.; Obara, Y. Effects of long-chain fatty acids on cytosolic triacylglycerol accumulation and lipid droplet formation in primary cultured bovine mammary epithelial cells. J. Dairy Sci. 2004, 87 (8), 2527-34.

(24) Fujimoto, Y.; Onoduka, J.; Homma, K. J.; Yamaguchi, S.; Mori, M.; Higashi, Y.; Makita, M.; Kinoshita, T.; Noda, J.; Itabe, H.; Takanoa, T. Long-chain fatty acids induce lipid droplet formation in a cultured human hepatocyte in a manner dependent of AcylCoA synthetase. Biol. Pharm. Bull. 2006, 29 (11), 2174-80.

(25) Artwohl, M.; Roden, M.; Waldhausl, W.; Freudenthaler, A.; Baumgartner-Parzer, S. M. Free fatty acids trigger apoptosis and inhibit cell cycle progression in human vascular endothelial cells. FASEB J. 2004, 18 (1), 146-8.

(26) Falconer, J. S.; Ross, J. A.; Fearon, K. C.; Hawkins, R. A.; O'Riordain, M. G.; Carter, D. C. Effect of eicosapentaenoic acid and other fatty acids on the growth in vitro of human pancreatic cancer cell lines. Br. J. Cancer 1994, 69 (5), 826-32.

(27) Guo, Y.; Walther, T. C.; Rao, M.; Stuurman, N.; Goshima, G.; Terayama, K.; Wong, J. S.; Vale, R. D.; Walter, P.; Farese, R. V. Functional genomic screen reveals genes involved in lipid-droplet formation and utilization. Nature 2008, 453 (7195), 657-61. 
Bodipy 493/503 and Nile Red (NR). ${ }^{27-29}$ These hydrophobic dyes are useful because they help to evaluate LD number, surface, volume and cellular distribution. ${ }^{27,29}$ Detecting changes in LD formation, size, and examining interactions between LDs and other organelles may be useful to elucidate the underlying mechanisms leading to the development of diseases in which lipid metabolism is impaired, such as obesity and diabetes. ${ }^{30,31}$

Results from the present studies suggest that cadmium telluride nanoparticles can induce formation of LD and cause marked changes in their morphology and proximity to lysosomes. We show that oleic acid treatment prior to the nanoparticle-induced oxidative stress enhances cell survival and prevents enlargement of lysosomes. Studies of interactions between nanoparticles and other nanomaterials with cellular organelles will eventually (i) aid in defining the most suitable structural properties which cause the least cellular damage, and (ii) define efficient ways of enhancing intrinsic cellular defenses to achieve maximal protection from possible nanomaterial insults.

\section{Experimental Section}

Cell Cultures. Rat pheochromocytoma cells (PC12) (ATCC, Rockville, MD) were cultured $\left(37^{\circ} \mathrm{C}, 5 \% \mathrm{CO}_{2}\right)$ in RPMI1640 (Gibco, Burlington, ON, Canada) medium containing $10 \%$ fetal bovine serum (FBS) (Gibco) and $0.01 \mathrm{M}$ Hepes buffer (Gibco).

Colocalization of LDs and Lysosomes in Live Cells. Live PC12 cells seeded $\left(7.5 \times 10^{3} /\right.$ well $)$ in poly D-lysine coated chambers slides (Lab-Tek, Nalge Nunc International, Rochester, NY) were stained with Bodipy 493/503 (38 $\mu \mathrm{M} / 10 \mathrm{~min}$ ) in RPMI1640. Cells were washed with PBS, and then lysosomes were stained with LysoTracker Red DND-99 (L-7528, MP) (500 nM/3 min) in RPMI1640. Cells were washed with PBS and taken to the confocal microscope for live imaging.

LysoTracker DND-99 (LTR) and Monodansylcadaverine (MDC) Staining in Live Cells. PC12 cells were seeded in 24-well plates (Sarstedt, \#83.1836) at a density of $5 \times 10^{4}$ cells/well and cultured overnight in complete culture medium. Cells were treated as indicated in figure legends, washed with PBS and stained with LTR $(500 \mathrm{nM})$ for $3 \mathrm{~min}$

(28) Diaz, G.; Melis, M.; Batetta, B.; Angius, F.; Falchi, A. M. Hydrophobic characterization of intracellular lipids in situ by Nile Red red/yellow emission ratio. Micron 2008, 39 (7), 819-24.

(29) Tavian, D.; Colombo, R. Improved cytochemical method for detecting Jordans' bodies in neutral lipid storage diseases. J. Clin. Pathol. 2007, 60 (8), 956-8.

(30) Bakker, S. J.; RG, I. J.; Teerlink, T.; Westerhoff, H. V.; Gans, R. O.; Heine, R. J. Cytosolic triglycerides and oxidative stress in central obesity: the missing link between excessive atherosclerosis, endothelial dysfunction, and beta-cell failure. Atherosclerosis 2000, 148 (1), 17-21.

(31) Cheng, H.; Guan, S.; Han, X. Abundance of triacylglycerols in ganglia and their depletion in diabetic mice: implications for the role of altered triacylglycerols in diabetic neuropathy. J. Neurochem. 2006, 97 (5), 1288-300. or MDC (Sigma, \#30432) $(50 \mu \mathrm{M})$ for $10 \mathrm{~min}$ at $37^{\circ} \mathrm{C}$ in RPMI1640. The dye was removed, and cells were washed with PBS. Images of subcellular compartments labeled with LTR and MDC were acquired at $40 \times$ with a Leica DFC350FX monochrome digital camera connected to a Leica DMI4000B inverted fluorescence microscope. Images were acquired and pseudocolored using Leica Application Suite (LAS) software. Relative fluorescence intensity of LTR in treated PC12 was measured with ImageJ (1.38) software.

Quantification of Lipid Droplet (LD) Number. PC12 were seeded $\left(5 \times 10^{4} /\right.$ well $)$ on 24 -well plates (Sarstedt, \#83.1836) and cultured overnight in serum-containing media. Cells treated as indicated in figure legends were washed with PBS and stained with Bodipy 493/503 (32 $\mu \mathrm{M} / 10 \mathrm{~min})$. Nuclei were labeled with Hoechst $33342(10 \mu \mathrm{M} / 30 \mathrm{~min})$. Fluorescent images of nuclei and LDs were acquired at $40 \times$ with a Leica DFC350FX monochrome digital camera connected to a Leica DMI4000B inverted fluorescence microscope. Images were acquired and pseudocolored using Leica Application Suite (LAS) software. LDs were counted using ImageJ (1.38) software.

Detection of Reactive Oxygen Species (ROS) and Superoxide Anion. Superoxide Detection. PC12 cells seeded $\left(2.5 \times 10^{4} /\right.$ well) on 96-well plates (Costar, \#3603) were treated with nanoparticles and hydrogen peroxide as described in the figure legends and incubated with dihydroethidium (DHE) (MP, D-11347) $(50 \mu \mathrm{M})$ for 30 min at $37^{\circ} \mathrm{C}$. Fluorescence of DHE was determined with a Fluostar Optima spectrofluorometer (BMG LabTech) using excitation and emission wavelengths of 544 and 590 $\mathrm{nm}$, respectively.

ROS Detection. PC12 cells seeded $\left(5 \times 10^{4} /\right.$ well $)$ on 24 well plates (Sarstedt) were treated as described in the figure legends and stained with $2^{\prime}, 7^{\prime}$-dichlorodihydrofluorescein diacetate (DCFH-DA) (MP, D-399) $(20 \mu \mathrm{M})$ for $30 \mathrm{~min}$ at $37{ }^{\circ} \mathrm{C}$.

Oleic Acid and Palmitic Acid Preparation. Oleic acid/ BSA complex was formed by the addition of $30 \mathrm{mg}$ of oleic acid (Sigma) and $50 \mathrm{mg}$ of palmitic acid (Sigma) to fatty acid free 5\% BSA (Sigma, A6003) solution. The stock solution concentration was adjusted to $4 \mathrm{mM}$ oleic acid or palmitic acid after determination with the NEFA C method kit (Wako). Aliquots of oleic and palmitic acid stocks (4 $\mathrm{mM}$ ) were stored at $-20{ }^{\circ} \mathrm{C}$.

Synthesis of CdTe Nanoparticles. All chemicals for CdTe nanoparticle preparation were from Sigma-Aldrich (Oakville, ON, Canada). $\mathrm{NaBH}_{4}$ (Sigma-Aldrich, Oakville, ON, Canada) $(0.8 \mathrm{~g}, 21.15 \mathrm{mmol})$ was dissolved in water $(20 \mathrm{~mL})$ at 0 ${ }^{\circ} \mathrm{C}$. Tellurium powder $(1.28 \mathrm{~g}, 10.03 \mathrm{mmol})$ was added portionwise, and the mixture was stirred at $0{ }^{\circ} \mathrm{C}$ under $\mathrm{N}_{2}$ for $8 \mathrm{~h}$, yielding a purple solution. The reaction mixture yielded NaHTe, which was kept at $4{ }^{\circ} \mathrm{C}$ in the dark. $\mathrm{Cd}\left(\mathrm{ClO}_{4}\right)_{2}(0.25 \mathrm{~mL}, 1 \mathrm{M}$ aqueous solution) and 3-mercaptopropionic acid (MPA; $0.2 \mathrm{~g}, 1.884 \mathrm{mmol}$ ) were dissolved in water $(200 \mathrm{~mL})$. The $\mathrm{pH}$ of the solution was adjusted to 10.5 using $1 \mathrm{M} \mathrm{KOH}$ prior to addition of NaHTe solution $(0.1 \mathrm{~mL})$. The reaction mixture became light brown in color 

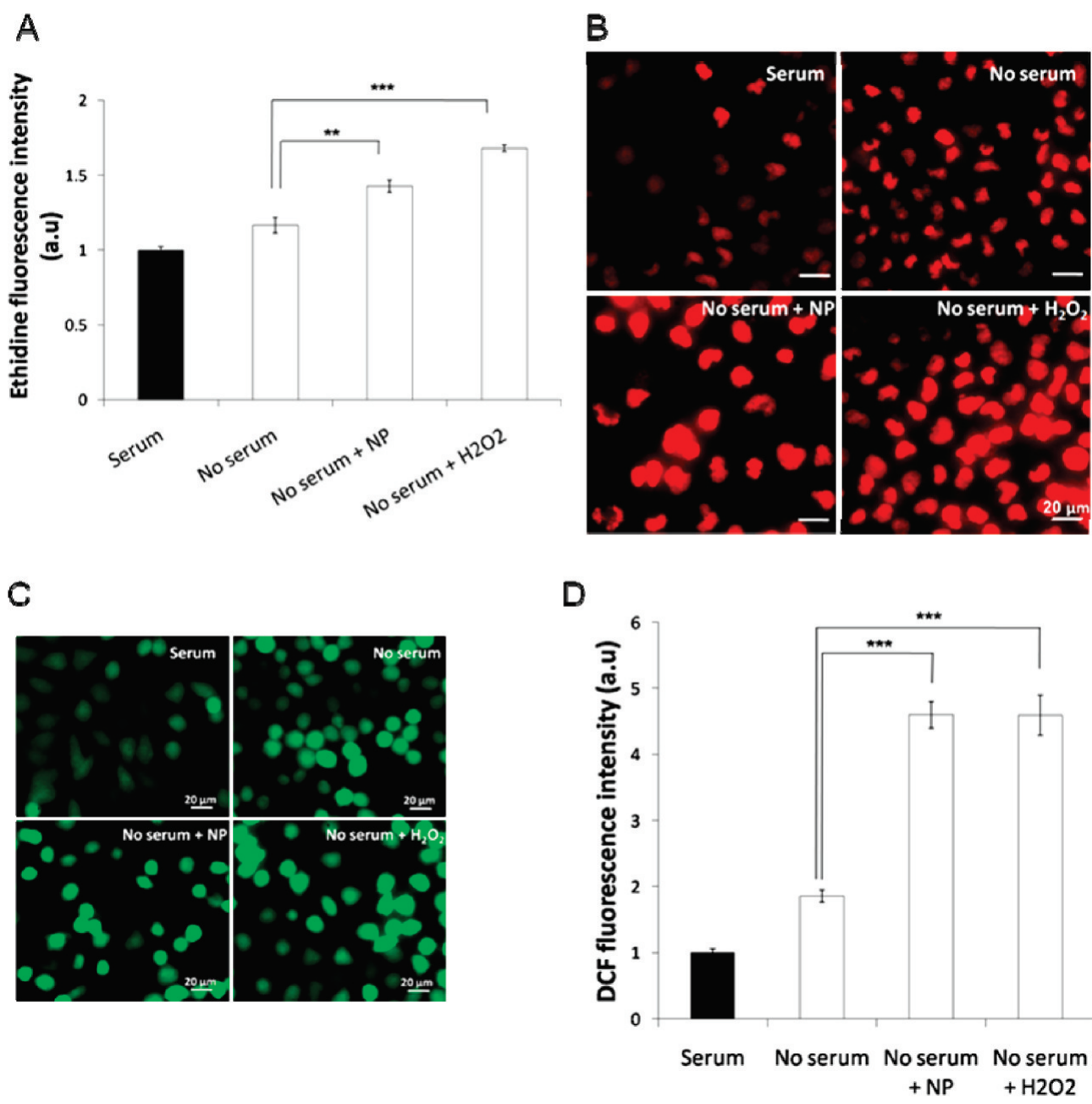

Figure 1. Increased oxidative stress in CdTe nanoparticle-treated cells. (A) Increased superoxide anion $\left(\mathrm{O}_{2}{ }^{-}\right)$ production in PC12 cells exposed to CdTe nanoparticles. Spectrofluorometric detection and quantification of dihydroethidium (DHE) staining in PC12 cultured in the presence or absence of serum and incubated with or without $\mathrm{CdTe}$ nanoparticles $(23 \mathrm{nM}, 24 \mathrm{~h})$ and $\mathrm{H}_{2} \mathrm{O}_{2}(10 \mu \mathrm{M})$ for $24 \mathrm{~h}$. Mean ethidine fluorescence intensity (arbitrary units) was normalized to number of cells and expressed relative to intensity of control (cells cultured in serum-containing medium). SEM was calculated from two independent experiments. Statistically significant differences are indicated by ${ }^{* * *} p<0.001$ or ${ }^{* *} p<0.005$. (B) Fluorescent microscopy of DHE stained PC12 cells under similar conditions as in panel A. Scale bar, $20 \mu \mathrm{m}$. (C) Enhanced production of reactive oxygen species (ROS) in CdTe nanoparticle-treated cells. Fluorescent micrographs showing DCFH-DA stained PC12 cultured in the presence or absence of serum and incubated with or without CdTe nanoparticles (23 nM, $24 \mathrm{~h})$ and $\mathrm{H}_{2} \mathrm{O}_{2}(10$ $\mu \mathrm{M})$ for $24 \mathrm{~h}$. Cells were stained with DCFH-DA (20 $\mu \mathrm{M}, 30 \mathrm{~min})$ Scale bar, $20 \mu \mathrm{m}$. (D) Semiquantification of DCF fluorescence intensity (arbitrary units) from experiments performed as described in panel C. Fluorescence intensity was measured with ImageJ and normalized to number of cells. Bar graphs indicate the mean fold increase in the fluorescence intensity (arbitrary units) of DCF over the control (cells cultured in serum-containing medium). Statistically significant differences are indicated by ${ }^{* *} p<0.001$ and were calculated from at least two independent experiments ( $n=4$ in each experiment).

and was heated to reflux. Aliquots were taken as the reaction proceeded, and the fluorescence spectra were recorded to monitor the nanoparticle growth as a function of reaction time. The maximum emission wavelength after $25 \mathrm{~min}\left(\lambda_{\mathrm{em}}\right.$ $=530 \mathrm{~nm})$ shifted to longer wavelengths as the reaction proceeded. The diameter of the CdTe nanoparticle core was determined by absorption/emission studies as described previously. ${ }^{32}$
MTT Assay for Cell Viability. PC12 cells seeded in 24well plates $\left(5 \times 10^{4}\right.$ cells/well $)$ were cultured overnight in serum-containing media. Serum-deprived cells were treated with oleic acid $(400 \mu \mathrm{M})$ and palmitic acid $(400 \mu \mathrm{M})$ for $24 \mathrm{~h}$ before exposure to CdTe nanoparticles $(23 \mathrm{nM})$ for $48 \mathrm{~h}$. MTT (3-(4,5-dimethylthiazol-2-yl)-2,5-diphenyl tetrazolium bromide, Sigma) was performed to assess the mitochondrial activity of cells. Treated cells were incubated with MTT $(0.5$ 

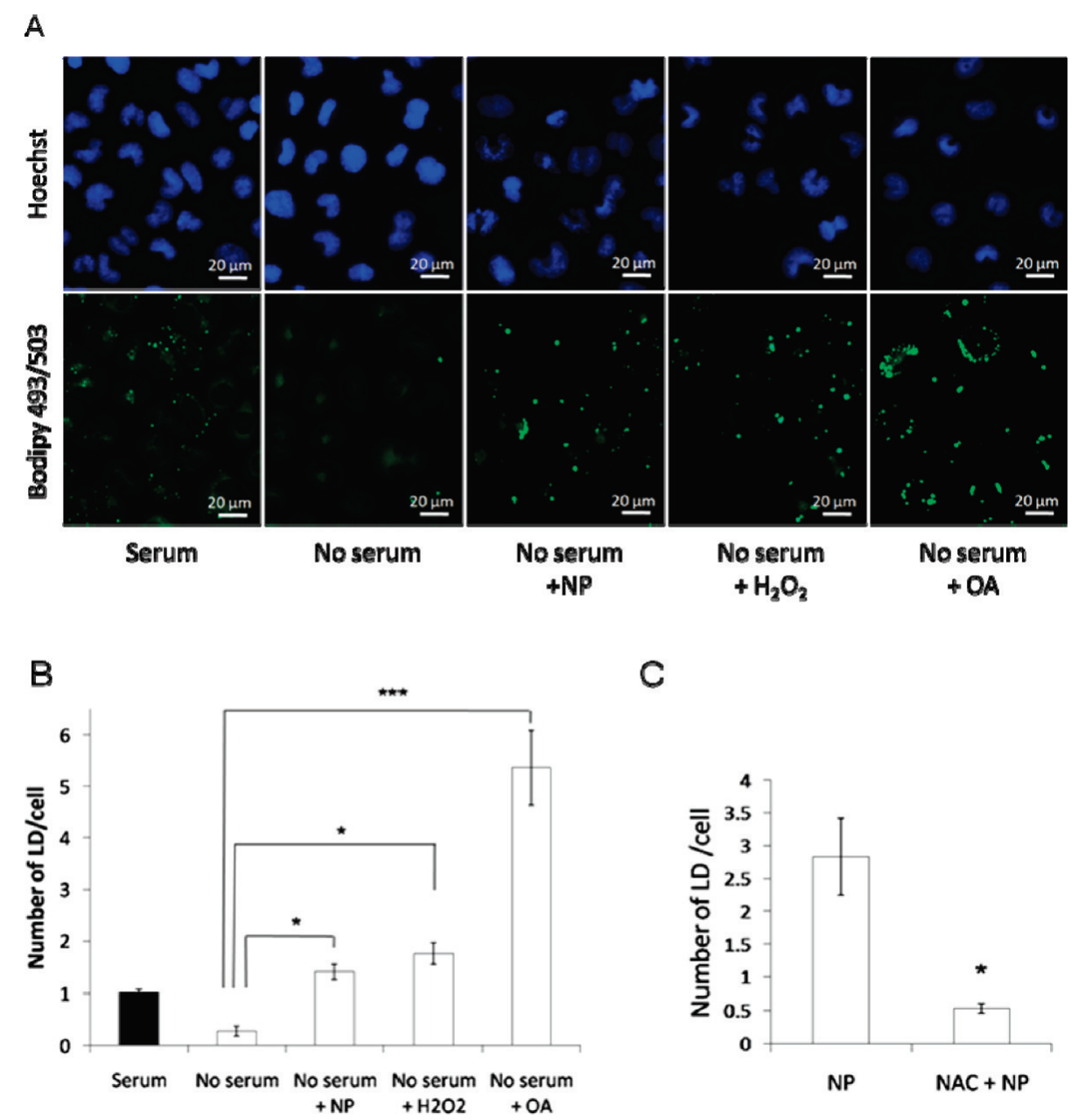

C

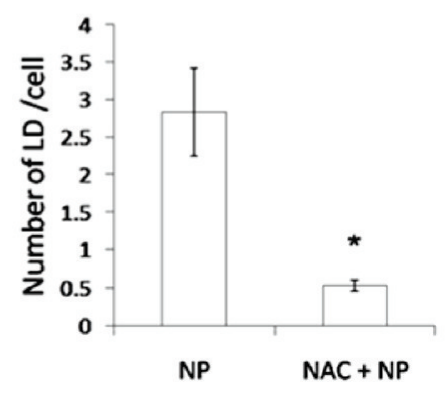

Figure 2. $\mathrm{LD}$ formation is induced by CdTe nanoparticles and $\mathrm{H}_{2} \mathrm{O}_{2}$ and blocked by antioxidant treatment. (A) LD staining in PC12 cultured in serum or deprived of serum and incubated with CdTe nanoparticles $(23 \mathrm{nM}), \mathrm{H}_{2} \mathrm{O}_{2}(10$ $\mu \mathrm{M})$ and oleic acid $(\mathrm{OA})(100 \mu \mathrm{M})$ for $24 \mathrm{~h}$. Nuclei and LDs were stained with Hoechst $33342(10 \mu \mathrm{M})$ and Bodipy 493/503 $(32 \mu \mathrm{M})$, respectively, as described in the Experimental Section. Scale bars, $20 \mu \mathrm{m}$. (B) Quantification of average LD number per cell from treatments in panel A. LDs counted in each field (6 fields/well) were normalized to the number of cells present in the field. Counting was performed with Image $\mathrm{J}$ software (1.38). (C) Reduced LD formation in cells pretreated with antioxidant NAC. PC12 cells were treated with NAC (2 mM) for 2 h before exposure to CdTe nanoparticles. Bar graphs show the mean of LD/cell and standard error of the means (SEM) from at least two independent experiments $(n=4$ in each experiment). Statistically significant differences are indicated by * $(p<$ $0.05)$ or ${ }^{* * *}(p<0.001)$.

$\mathrm{mg} / \mathrm{mL}$ ) for $1 \mathrm{~h}$ at $37^{\circ} \mathrm{C}$, after which media were removed and cells were lysed with DMSO (Sigma). Absorbance was measured at $595 \mathrm{~nm}$ using a Benchmark microplate reader (Bio-Rad, Mississauga, ON, Canada). All measurements were performed in quadruplicate.

Confocal and Transmission Electron Microscopy (TEM). Images were acquired with a Zeiss LSM 510 NLO inverted microscope. Lysosomes were stained with LysoTracker Red DND-99 ( $\left.\lambda_{\text {ex }} 577 \mathrm{~nm}, \lambda_{\text {em }} 590 \mathrm{~nm}\right)$ and imaged with the HeNe $543 \mathrm{~nm}$ laser using a LP 560 filter. LDs stained with Bodipy $493 / 503\left(\lambda_{\mathrm{ex}} 493 \mathrm{~nm}, \lambda_{\mathrm{em}} 503 \mathrm{~nm}\right)$ were visualized using Argon 488 laser and the BP 505-550 filter. Images were acquired at a resolution of $1024 \times 1024$.

The status of PC12 cells subcellular organelles was assessed by JEOL JEM-2000FX TEM operating at an accelerating voltage of $80 \mathrm{kV}$. Cells in monolayers with or without CdTe nanoparticle treatment were fixed with $4 \%$ paraformaldehyde, and cut using an Ultracut-E ultramicrotome (Reichert-Jung, Leica Microsystems, Austria). The ultrathin sections were transferred onto 200-mesh copper grids (Electron Microscopy Sciences). The grids were then doubly stained with uranyl acetate (negative stain for background) and Reynolds lead citrate stain (provides contrast for cellular membranes).

Statistics. Statistical analysis was performed using Systat (version 10.2). Two sample $t$ test was used when only two groups were being compared. Multiple comparisons were done with one way ANOVA, followed by Bonferroni's correction posthoc test. All data are presented as group means \pm SEM. $p<0.05$ was considered significant.

VOL. 6 , NO. 4 MOLECULAR PHARMACEUTICS 

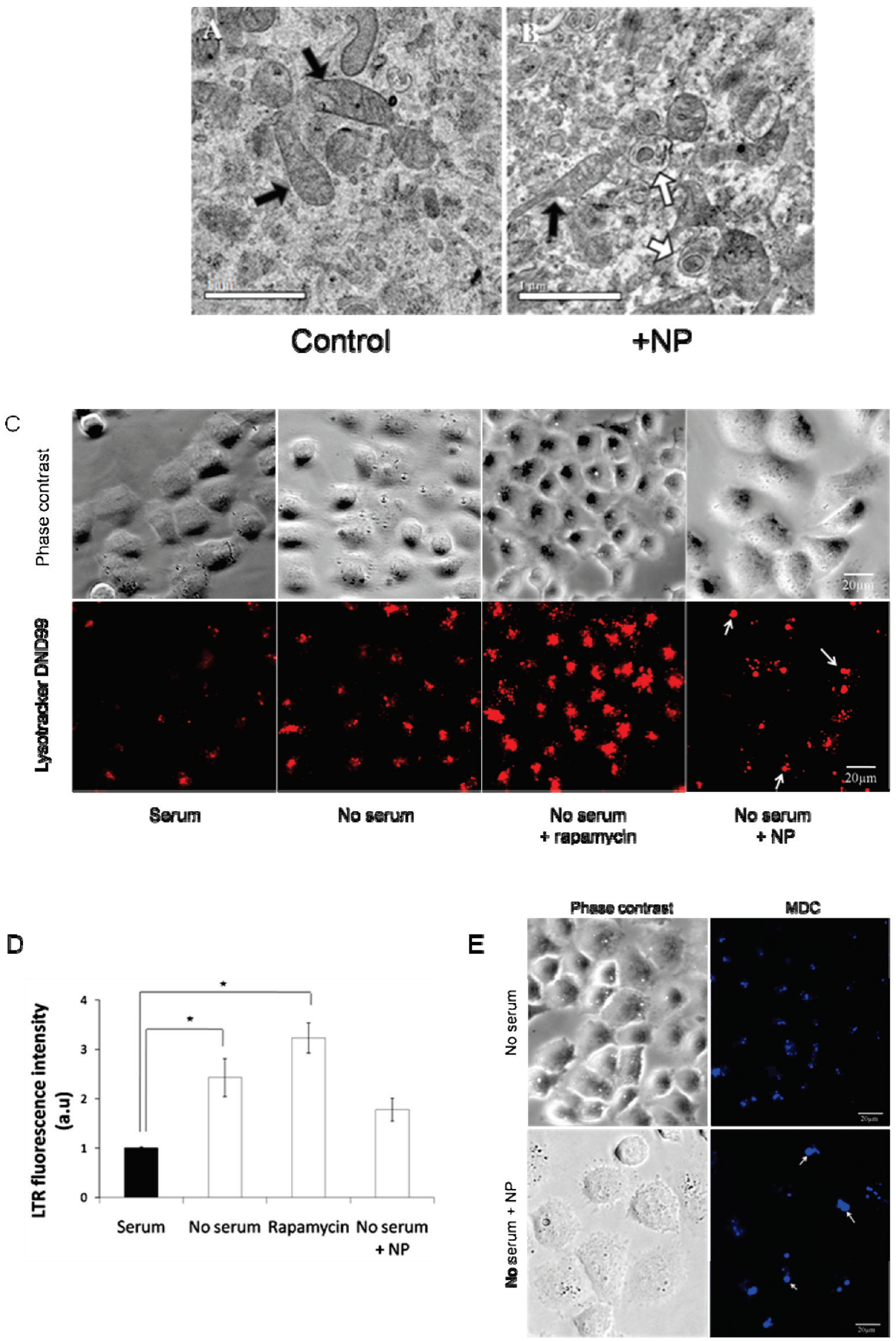


\section{Results}

Increased Production of Reactive Oxygen Species (ROS) Following CdTe Nanoparticle Treatment. CdTe spherical nanoparticles (diameter $=2.8 \mathrm{~nm}$ ) consist of a cadmium telluride core and do not have a zinc sulfide protecting cap, commonly used to stabilize the nanoparticle. ${ }^{33}$ The coating with mercaptopropionic acid (MPA) increases nanoparticle hydrophilicity and renders the surface negative. It was previously shown that ROS are produced in PC12 cells exposed to CdTe nanoparticles. ${ }^{14}$ In order to demonstrate generation of superoxide anion $\left(\mathrm{O}_{2}{ }^{-}\right)$, dihydroethidium (DHE) was used. DHE oxidation by $\mathrm{O}_{2}{ }^{-}$results with ethidine, which intercalates with cellular DNA, yielding bright red, fluorescent nuclear staining. Hydrogen peroxide $\left(\mathrm{H}_{2} \mathrm{O}_{2}\right)(10 \mu \mathrm{M})$, known for its capacity to generate ROS such as $\mathrm{O}_{2}^{-}$in different cell types, was used as a positive control during DHE staining experiments. $^{34,35}$ Spectrofluorometric measurements of ethidine fluorescence showed significant increase in fluorescence intensity in cells treated with CdTe nanoparticles $(23 \mathrm{nM})(26 \%, p<0.001)$ and $\mathrm{H}_{2} \mathrm{O}_{2}(52 \%, p<$ 0.001 ) relative to nontreated (serum-deprived cells) (Figure 1A). These data are supported by fluorescent micrographs of DHE-stained cells under similar conditions (Figure 1B). In order to examine production of total intracellular ROS, we stained the cells with a general marker for ROS, $2^{\prime}, 7^{\prime}$ dichlorodihydrofluorescein diacetate (DCFH-DA). Within the cell, DCFH-DA is deacetylated and easily oxidized to $2^{\prime}, 7^{\prime}$-dichlorofluorescein (DCF), a highly fluorescent compound (excitation, $485 \mathrm{~nm}$; emission, $530 \mathrm{~nm}$ ). ${ }^{36}$ Fluorescent micrographs of DCFH-DA-stained cells show increased DCF fluorescence intensity inside individual cells following serum starvation $(24 \mathrm{~h})$, and incubation with $\mathrm{CdTe}$ nanoparticles and $\mathrm{H}_{2} \mathrm{O}_{2}$ (Figure 1C). An assessment of DCF fluorescence intensity shows an increase of about 2-fold in serum-deprived cells and of more than 4-fold when cells were incubated with CdTe nanoparticles and $\mathrm{H}_{2} \mathrm{O}_{2}$, when compared with cells cultured in serum (Figure 1D).
Status of Lipid Droplets and Lysosomes in Cells Exposed to CdTe Nanoparticles. We first examined LD formation under nanoparticle-induced oxidative stress by staining the cells with Bodipy 493/503, a neutral lipid selective dye. ${ }^{29}$ LDs are sparse but detectable in PC12 grown in serum-containing medium, whereas they are very low in serum-starved cells in the absence of CdTe nanoparticles (23 $\mathrm{nM}, 24 \mathrm{~h})$ or $\mathrm{H}_{2} \mathrm{O}_{2}(10 \mu \mathrm{M}, 24 \mathrm{~h})$ (Figure 2A). Average LD number per cell (LD/cell) decreased by about 4 -fold in cells deprived of serum, as compared to cells cultured in serumcontaining media (Figure 2B). In contrast, LD were formed in serum-deprived cells exposed to CdTe nanoparticles, $\mathrm{H}_{2} \mathrm{O}_{2}$ or oleic acid (Figure 2A). LD/cell was increased by 5 -fold $(p<0.05)$ and by about 6 -fold $(p<0.05)$ in cells exposed to CdTe nanoparticles and $\mathrm{H}_{2} \mathrm{O}_{2}$, respectively, when compared to serum-starved cells. Oleic acid treatment $(100 \mu \mathrm{M}, 24 \mathrm{~h})$, which served as a positive control, caused almost a 20 -fold increase in LD/cell in serum-starved cells $(p<0.001)$ (Figure 2B). To demonstrate that increased LD formation is caused by oxidative stress, cells were pretreated with antioxidant molecule $N$-acetylcysteine (NAC) $(2 \mathrm{mM})$. The pretreatment significantly $(p<0.05)$ reduced LD formation in cells exposed to CdTe nanoparticles, compared to nonpretreated cells (Figure 2C).

We next examined mitochondrial and lysosomal status in cells exposed to nanoparticles in starved PC12 cells. The mitochondrion is the metabolic center and the major free radical-producing compartment of the cell. ${ }^{37}$ Lysosomes are the central components of the autophagic degradative pathway and are highly susceptible to oxidative stress. ${ }^{38}$ Examining the morphology of lysosomes and their cellular distribution may provide new information on the impact of CdTe nanoparticles on lysosomal integrity. Electron microscopy data (Figure 3A, Figure 3B) show that $\mathrm{CdTe}$ nanoparticles induce ultrastructural changes in PC12, including disrupted mitochondrial cisternae (Figure 3B, black arrows) and appearance of large phagosomes (Figure 3B, white arrows) suggesting increased autophagy. Some metallic nanoparticles were recently reported to be inducers of autophagy. ${ }^{16-18}$ The impact of $\mathrm{CdTe}$ nanoparticles on cellular lysosomal

Figure 3. Phagosome appearance and enlargement of lysosomal compartments in PC12 cells exposed to nanoparticles. (A, B) Electron micrographs showing ultrastructural changes in nanoparticle-treated cells. PC12 cells were cultured in serum-containing media (control) or deprived of serum and incubated with CdTe nanoparticles (23 $\mathrm{nM}$ ) for $24 \mathrm{~h}$. Mitochondrial structure (black arrows) is disrupted and phagosomes (white arrows) appear in nanoparticle-treated cells. Scale bar, $1 \mu \mathrm{m}$. (C) CdTe nanoparticles cause enlargement of acidic lysosomal compartments in PC12 cells. Cells were cultured in serum-containing media or deprived of serum and treated with either rapamycin $(200 \mathrm{nM})$ or CdTe nanoparticles $(23 \mathrm{nM})$ for $24 \mathrm{~h}$. Fluorescent micrographs show lysosomes (red) stained with LysoTracker DND-99 (LTR) $(500 \mathrm{nM})$. Scale bars, $20 \mu \mathrm{m}$. (D) Quantification of LTR fluorescence intensity (arbitrary units) in images from Figure 1C. LTR fluorescence intensity was measured with ImageJ and normalized to number of cells. Standard errors of the means (SEM) were calculated from at least two independent experiments $(n=$ 3 in each experiment) and expressed as fold increase over the control (cells cultured in serum). Statistically significant differences are indicated by ${ }^{*} p<0.05$. (E) Nanoparticle-induced enlargement of acidic autophagic vacuoles detected by monodansylcadaverine (MDC) staining. PC12 cells were deprived of serum and incubated with CdTe nanoparticle $(23 \mathrm{nM})$ for $24 \mathrm{~h}$. Acidic autophagic vacuoles are stained with blue autofluorescent dye MDC (50 $\mu \mathrm{M})$ for $10 \mathrm{~min}$. Scale bars, $20 \mu \mathrm{m}$. 


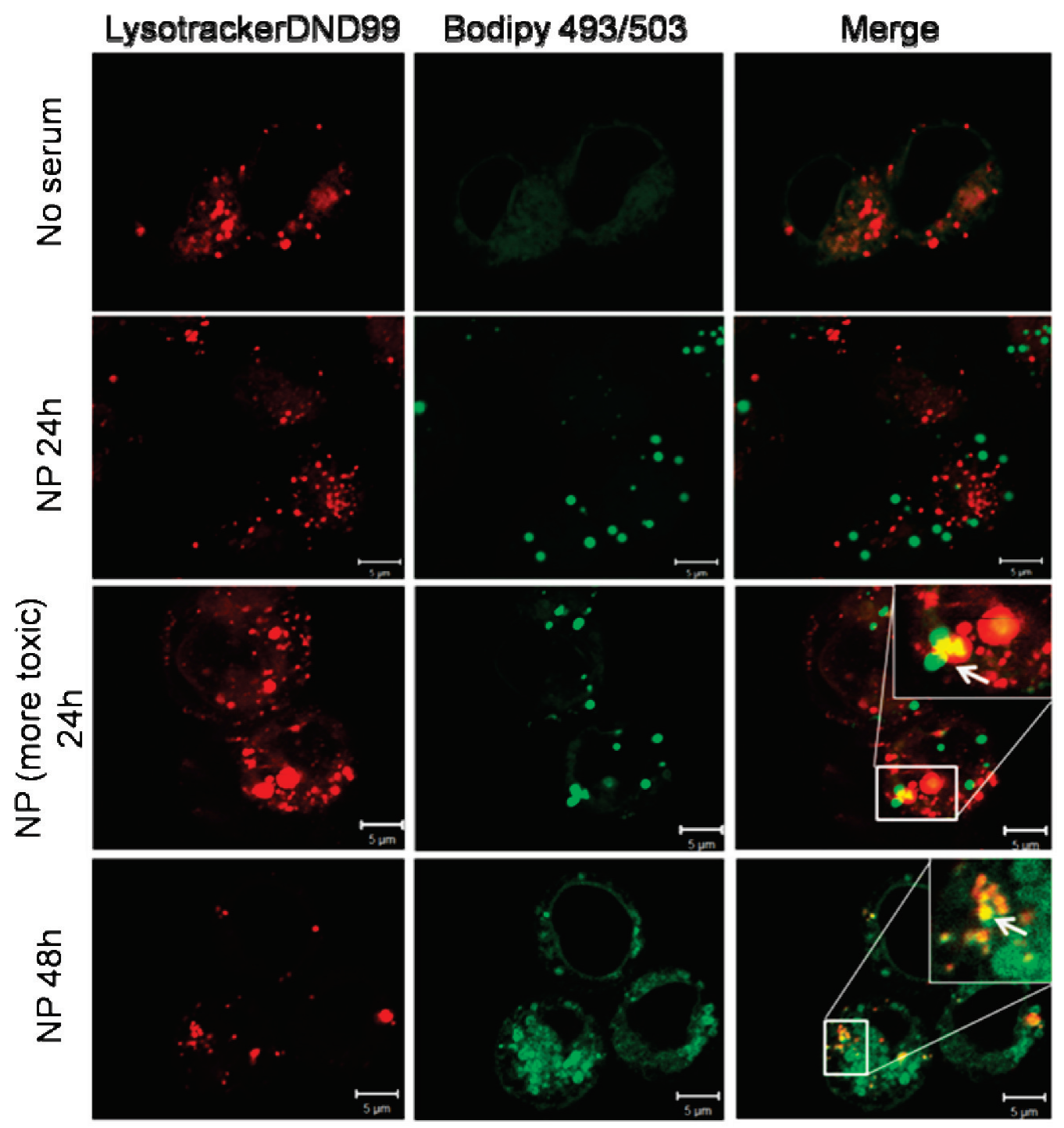

Figure 4. Relative localization of LDs and lysosomes in cells exposed to CdTe nanoparticles. PC12 cells seeded on confocal chamber slides were deprived of serum and incubated with CdTe nanoparticles $(23 \mathrm{nM})$ for $24 \mathrm{~h}$ and $48 \mathrm{~h}$. LDs were labeled with Bodipy 493/503 (38 $\mu \mathrm{M})$ and lysosomes with LTR (500 nM). LD-lysosomal colocalization is indicated by white arrows in the insets. Colocalization between the organelles was detected under long term (48 h) and short term (24 h) with treatment of highly toxic "aged" CdTe nanoparticles. Scale bars, $5 \mu \mathrm{m}$.

content and morphology in living PC12 cells was assessed by LysoTracker DND-99 (LTR) staining. LTR fluorescence intensity increased by $(2.43 \pm 0.38)$-fold $(p<0.05)$ in serum-deprived cells and by $(3.23 \pm 0.31)$-fold $(p<$ $0.05)$ in rapamycin-treated cells, as compared to control cells (Figure 3C, Figure 3D). CdTe nanoparticle treatment caused enlargement of lysosomes, whereas serum starvation and rapamycin treatment seem to increase their number, but not their size (Figure 3C). Such large structures in CdTe nanoparticle-exposed cells were also detected with monodansylcadaverine (MDC) (Figure 3E, arrows), an autofluorescent dye specific to acidic autophagic vacuoles. ${ }^{39}$

We hypothesized that LDs and lysosomes in CdTe nanoparticle-stressed PC12 cells may be found in close proximity. Interactions of LDs with various organelles were reported in several cell types, but the biological functions behind these interactions are not fully understood. We therefore examined changes in proximity between LDs and lysosomes in cells undergoing oxidative stress. As shown previously, LDs were not detected in serum-starved PC12 cells (Figure 4). LDs were formed in cells incubated with CdTe nanoparticles ( $23 \mathrm{nM}, 24 \mathrm{~h}$ ), but did not colocalize with lysosomes. However, LDs detected in cells exposed to nanoparticles for $48 \mathrm{~h}$ were found in the proximity of lysosomes suggesting possible colocalization between these two organelles. A similar pattern was also seen in cells exposed to highly toxic "aged" CdTe nanoparticles in (23 $\mathrm{nM}, 24 \mathrm{~h}$ ) (Figure 4 and Figure 1 in the Supporting Information). In order to validate our observations on the colocalization of lipid droplets with lysosomes at the $24 \mathrm{~h}$ time point, we performed 3D isosurface reconstruction of the organelles using the image analysis software Imaris 
(Bitplane Inc.) (Figure 1B in the Supporting Information). The analysis clearly shows that some of the lipid droplets are found within the lysosomes, thereby supporting the colocalization seen in confocal micrographs. Oleic acid (400 $\mu \mathrm{M})$ also induced LD formation, but these LDs did not colocalize with lysosomes (Figure 2 in the Supporting Information).

Cell Viability, LD Status and Lysosomal Morphology in Oleic Acid Primed Cells. LD biogenesis was recently shown to be cytoprotective during stress induced by glucose deprivation. ${ }^{40}$ In order to examine the possible role of $\mathrm{LD}$ in PC12 cell survival under oxidative stress, we tested the effects of oleic acid and palmitic acid (PA) preconditioning in nanoparticle-treated and serum-starved cells. We set the control (cells grown in serum-containing medium) to $100 \%$ and expressed the other values as a percent of control. Trophic factor withdrawal $(48 \mathrm{~h})$ led to a significant decrease in cell viability $(40.6 \pm 0.6 \%, p<0.001)$, compared to cells grown in complete medium $(100 \pm 1.5 \%)$, as determined by MTT reduction (Figure 5A). Priming the cells with oleic acid $(400 \mu \mathrm{M})$ partially prevented serum withdrawal-induced decrease in cell viability $(76.4 \pm 1.4 \%$, compared to $40.6 \pm$ $0.6 \%$, respectively, $p<0.001)$. Priming with PA, a saturated fatty acid $(400 \mu \mathrm{M})$, however, exerted the opposite effect of oleic acid: PA induced cell death $(11.7 \pm 1.4 \%, p<0.001)$, whereas oleic acid preconditioning significantly rescued cells $(59.5 \pm 1.7, p<0.001)$ from CdTe nanoparticle/serum withdrawal-induced cell death $(20.0 \pm 1 \%, p<0.001)$. The gain of cell viability by oleic acid priming under serum withdrawal and nanoparticle/serum withdrawal treatment was not much different (36\% and $40 \%$ ). In order to examine the rescue by oleic acid from toxicity alone, we exposed cells to CdTe nanoparticles while keeping them in serumcontaining media. The viability of untreated cells cultured in the presence of serum was set as control (100\%). Priming with oleic acid $(95.6 \pm 1.1 \%)$ prevented some of the CdTe nanoparticle induced-cell death $(82.8 \pm 0.4 \%)$ following $48 \mathrm{~h}$ treatment (Figure 3 in the Supporting Information). However, priming with PA further decreased cell viability (36.9 \pm $3.4 \%$ ) under CdTe nanoparticle treatment. These results suggest that the protective effect of oleic acid is at least partly due to the rescue from CdTe NP-inflicted toxicity. It was previously proposed that triglycerides in LDs may be utilized

(32) Yu, W. W.; Qu, L.; Guo, W.; Peng, X. Experimental Determination of Extinction Coefficient of CdTe, CdSe, and $\mathrm{CdS}$ Nanocrystals. Chem. Mater. 2003, 15 (14), 2854-2860.

(33) Derfus, A. M.; Chan, W. C. W.; Bhatia, S. N. Probing the Cytotoxicity of Semiconductor Quantum Dots. Nano Lett. 2004, 4 (1), 11-18.

(34) Satoh, T.; Enokido, Y.; Aoshima, H.; Uchiyama, Y.; Hatanaka, $\mathrm{H}$. Changes in mitochondrial membrane potential during oxidative stress-induced apoptosis in PC12 cells. J. Neurosci. Res. 1997, 50 (3), 413-20.

(35) Viola, H. M.; Arthur, P. G.; Hool, L. C. Transient exposure to hydrogen peroxide causes an increase in mitochondria-derived superoxide as a result of sustained alteration in L-type $\mathrm{Ca} 2+$ channel function in the absence of apoptosis in ventricular myocytes. Circ. Res. 2007, 100 (7), 1036-44. as fuel and prolong cell survival during starvation and oxidative stress. ${ }^{2,40,41}$ An assessment of LD using Bodipy 493/503 staining after $48 \mathrm{~h}$ of incubation with CdTe nanoparticles revealed presence of many LDs only in cells primed with oleic acid (Figure 5B).

In order to determine whether the protection by oleic acid could be due to the prevention of CdTe nanoparticle-induced lysosomal membrane destabilization (organelle enlargement) (see Figure 3), we investigated lysosomal morphology during long-term serum deprivation $(48 \mathrm{~h})$ and CdTe nanoparticle treatment (48 h) with or without oleic acid preconditioning. Serum-deprived PC12 showed a weak lysosomal staining (Figure 5C, first row), which was increased in cells preconditioned with oleic acid (Figure 5C, second row). CdTe nanoparticles caused excessive enlargement of lysosomes (Figure 5C), as previously observed (Figure 3C), which was prevented by oleic acid preconditioning, suggesting that priming with oleic acid improved stability of lysosomes.

\section{Discussion}

Results from these studies show that some metallic, i.e. CdTe "naked" nanoparticles induce lipid droplet formation. Oleic acid treatment also induced LD formation and it provides fuel needed for survival under starvation conditions; it also prevents excessive expansion of lysosomal membranes under nanoparticle-induced oxidative stress, thereby providing cytoprotection under such conditions.

Several studies, including ours, have shown that some nanoparticles can induce oxidative stress leading ultimately to cell death. ${ }^{13,14} \mathrm{CdTe}$ nanoparticle-induced oxidative stress is partly caused by the release of cadmium ions from the nanoparticle core, but the concentration of the cadmium ions in the medium did not induce significant LD formation (unpublished observation). An early in vivo study proposed that high tellurium ion concentrations cause LD formation in Schwann cells and that their accumulation can be explained by increase in cholesterol precursor, squalene. ${ }^{42}$ This mechanism is unlikely because free tellurium concentrations here are far below those reported to induce LDs. Oxidative stress-induced LD accumulation is well studied and has been demonstrated under hypoxic conditions, irradiation and treatments with chemotherapeutic agents. ${ }^{43-46}$ Recently, Gubern et al. demonstrated that triglyceride synthesis and LD biogenesis during stress mainly takes place from pre-existing fatty acids and is dependent on group VI phospholipase $\mathrm{A}_{2}$ ( $\mathrm{PLA}_{2}$-VIA). ${ }^{40}$ One possible explanation for $\mathrm{LD}$ accumulation is the impairment in mitochondrial fatty acid $\beta$-oxidation, resulting from mitochondrial membrane

(36) Bland, E. J.; Keshavarz, T.; Bucke, C. Using 2', 7'-dichlorodihydrofluorescein-diacetate to assess polysaccharides as immunomodulating agents. Mol. Biotechnol. 2001, 19 (2), 125-31.

(37) Chaturvedi, R. K.; Beal, M. F. Mitochondrial approaches for neuroprotection. Ann. N.Y. Acad. Sci. 2008, 1147, 395-412.

(38) Butler, D.; Bahr, B. A. Oxidative stress and lysosomes: CNSrelated consequences and implications for lysosomal enhancement strategies and induction of autophagy. Antioxid. Redox Signaling 2006, 8 (1-2), 185-96. 


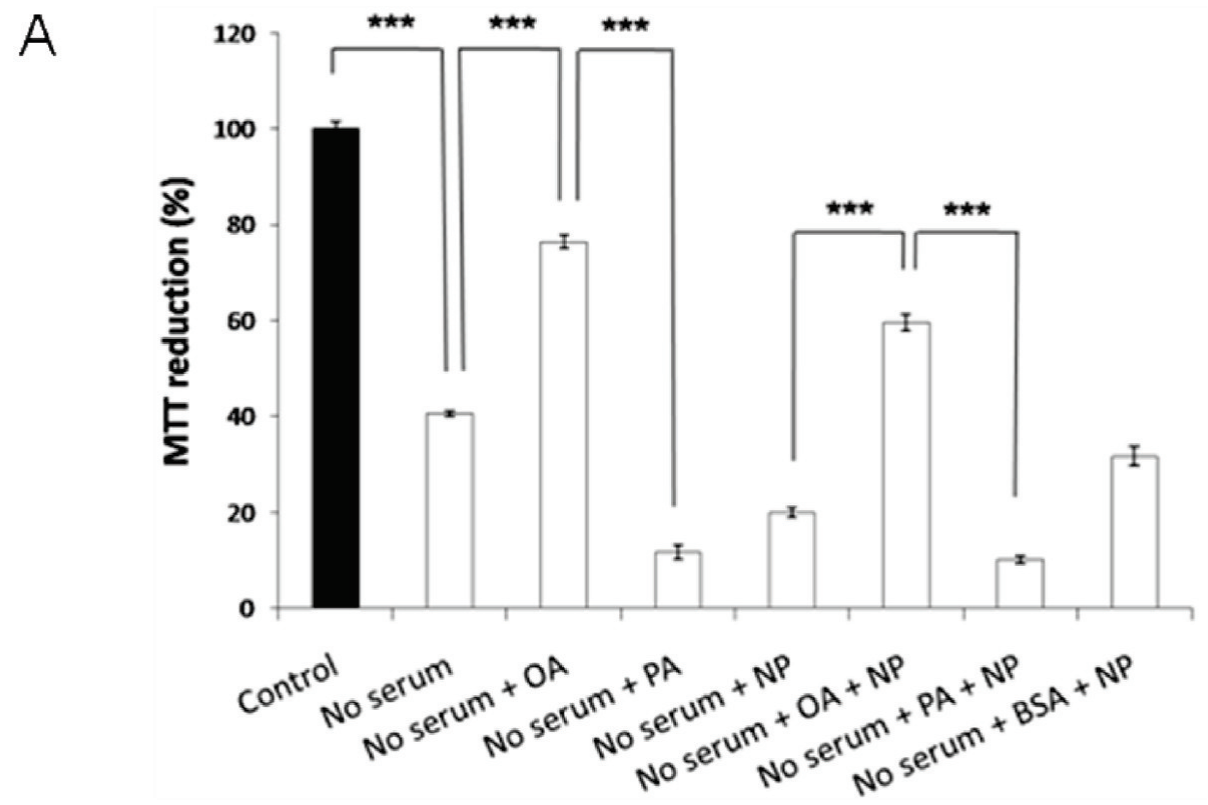

B

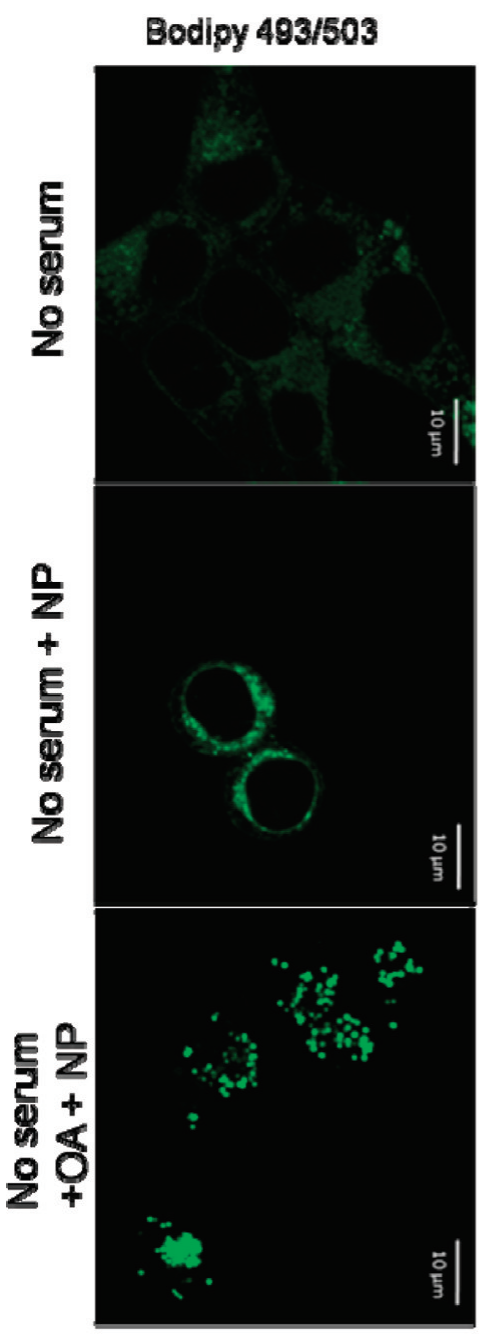

C LysotrackerDND99 Hoechst

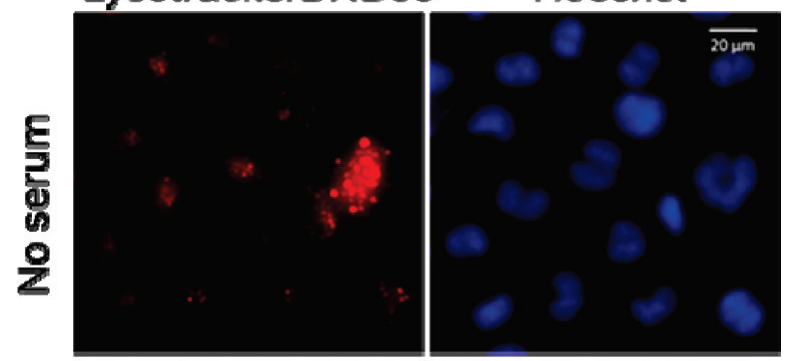

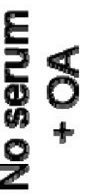
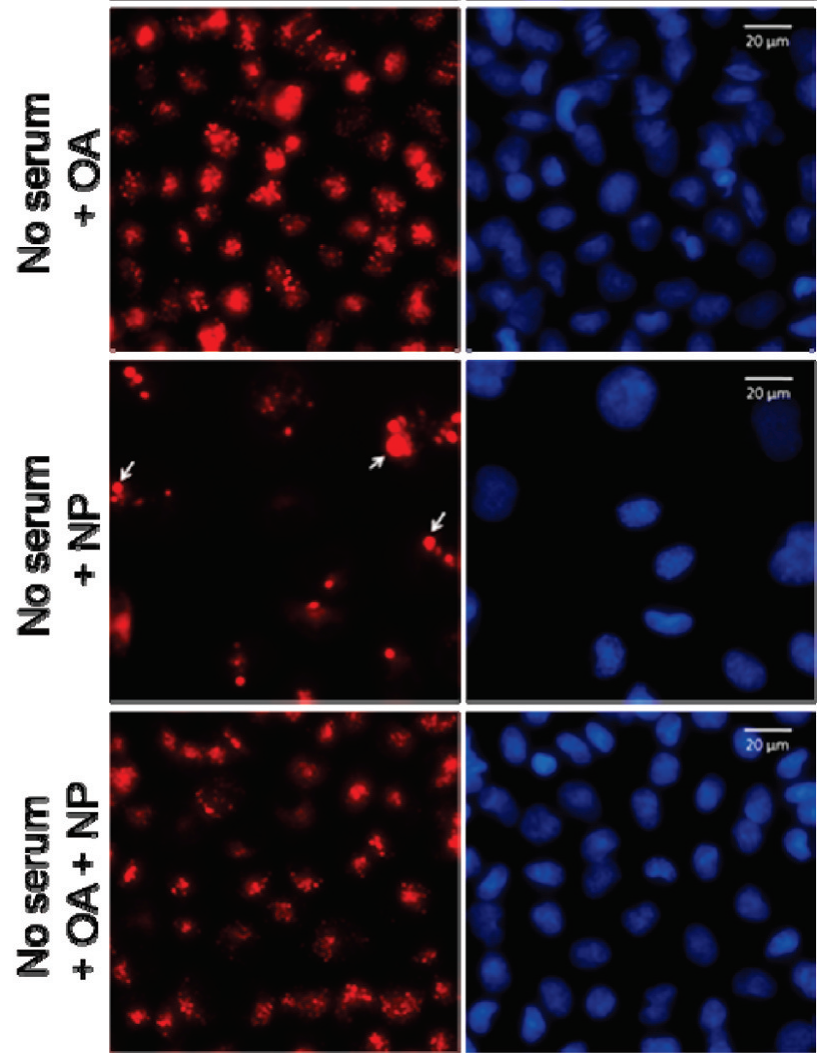
damage, and leading to an increase in triglyceride storage. ${ }^{14,47,48}$ Results from our studies suggest that assessment of LD accumulation may serve as a biological marker of oxidative stress and indicate disrupted lipid homeostasis by nanomaterials.

Lysosomes are major organelles involved in the degradation of damaged intracellular organelles (e.g., mitochondria) in autophagy, and they are fierce responders to oxidative stress. ${ }^{49,50}$ Autophagy (cell "self-eating") usually occurs in nutrient or growth factor deprived cells. ${ }^{49}$ It was shown that autophagy plays an instrumental role in serum deprivationinduced cell death in PC12 cells, and that lysosomes are involved in this process. ${ }^{51-53}$ In the present work, serumstarved PC12 cells showed a significant increase in lysosomal staining relative to nonstarved controls (Figure 3C,D), suggesting an increased autophagy. Similarly, rapamycin, commonly used to induce autophagy, significantly increased the fluorescence intensity of lysosomal marker LysoTracker DND-99. ${ }^{17,54}$ Electron micrographs of CdTe nanoparticletreated PC12 cells revealed membrane-bounded vacuoles containing cytoplasmic structures. Such vacuoles were previously observed in serum-starved PC12 cells and identified as autophagosomes or autolysosomes. ${ }^{55}$ In the autophagiclysomal pathway, cytoplasmic contents are engulfed by the autophagosomes and degraded in the autolysosomes upon their fusion with lysosomes. ${ }^{56}$ The enlargement of acidic compartments in cells exposed to CdTe nanoparticles (Figure $3 \mathrm{C}$ and Figure 5C) could be caused by lysosomal membrane destabilization under oxidative stress or by the overflow of cytoplasmic contents (e.g. organelles) into lysosomes due to an increased autophagy. ${ }^{15,56,57}$ Lysosomal membrane impairments are partly caused by free cadmium ions released from the CdTe nanoparticle core. ${ }^{12}$ An excessive damage of the lysosomal membranes by cytotoxic nanoparticles could lead to the leaching of hydrolytic enzymes outside of the organelle, leading to apoptotic or necrotic cell death. ${ }^{50,58}$

Lipid droplets are currently considered to be metabolically active organelles, and their behavior in stressed cells is intriguing, as lipid metabolism is impaired during oxidative stress. ${ }^{59,60}$ Only very limited information is available for communications between lysosomes and LD. Liu et al. identified proteins that are common between LD and lysosomes, such as Rab7 and SNAP, suggesting a possible link between these organelles. ${ }^{61} \mathrm{LD}$ are consistently associated with phagolysosomes in macrophages during in vivo infection, and some are even internalized by the phagolysosomes. ${ }^{62}$ In the present study, we examined colocalization of LD with lysosomes in starved PC12 cells exposed to CdTe nanoparticles for up to $48 \mathrm{~h}$. Lysosome-LD colocalization was detected after $24 \mathrm{~h}$ exposure to highly toxic nanoparticles, but considerably later ( $48 \mathrm{~h}$ ) with less toxic nanoparticles. The term "highly toxic" is used to indicate "aged" (degenerate) nanoparticles as compared to those used shortly after their preparation. Enlargement of lysosomal compartment in the cells exposed to "aged" CdTe nanoparticles is striking and reflects excess cellular stress. ${ }^{57}$ The present study carried out with living PC12 cells suggests close apposition between LD and acidic organelles (e.g lysosomes) labeled with LysoTracker DND-99; the identity of lysosomes should be confirmed in future studies by immunocytochemisty using LAMP1 antibodies or in cells expressing organelle-specific proteins tagged with green fluorescent protein (GFP) family members. Detailed studies employing these approaches in combination with wet electron microscopy could provide more information on lysosome-LD interactions and on their role in different cell functions.

Oleic acid is commonly used in investigations on LD biogenesis, morphology, proteomics and cytoplasmic distribution. ${ }^{27}$ In the current study oleic acid was used for induction of LD to assess their protective role in cells under oxidative stress and nutrient deprivation. Assessment of cell viability clearly shows that priming with oleic acid, but not with saturated fatty acid palmitic acid (PA), provides effective cell rescue, as evidenced by enhanced mitochondrial metabolic activity and cell viability (Figure 5A). PA exacerbates nanoparticle- and nutrient deprivation-induced cell death. Other groups have shown that PA, in similar concentrations (300 to $500 \mu \mathrm{M}$ ), exerts lipotoxic effects and induces apoptosis. ${ }^{63,64}$ Lipotoxicity resulting from the accumulation of long chain fatty acids seems to be caused predominantly by saturated fatty acids. ${ }^{63}$ Conversely, oleic acid supplementation is well-tolerated by the cells, leads to triglyceride (TG) accumulation and protects the cells against saturated fatty acid-induced lipotoxicity. ${ }^{65}$ Recently, Du et al. proposed that triglycerides stored within LD can be utilized for fuel in starving neurons, thereby increasing their viability. ${ }^{41}$ Our studies are in line with these findings and suggest that LD

Figure 5. Nanoparticle-induced cell death and oleic acid-mediated rescue during long-term oxidative stress. (A) PC12 cells preconditioned with oleic acid (OA) but not palmitic acid (PA) are partially rescued from CdTe nanoparticle-induced cell death. Cells were primed with oleic acid $(400 \mu \mathrm{M})$, palmitic acid $(400 \mu \mathrm{M})$ or BSA $(0.5 \%)$ for $24 \mathrm{~h}$ in the absence of serum. They were washed and incubated in serum-free media for $48 \mathrm{~h}$ with or without CdTe nanoparticle treatment $(23 \mathrm{nM})$. Cell viability was determined by using the MTT reagent. Data obtained from three independent experiments ( $n=4$ in each experiment) are expressed as the mean (\%) \pm standard error of the mean (SEM). Statistically significant differences are indicated by ${ }^{* * *} p<0.001$. (B) LDs are maintained only in oleic acid-primed cells. All treatments were carried out in serum-free media with or without nanoparticle treatment. Bodipy 493/503 staining shows the presence of numerous LD in oleic acid (OA) + CdTe nanoparticles panel. Scale bars, 10 $\mu \mathrm{m}$. (C) Effect of oleic acid preconditioning on lysosomal morphology in serum-starved and nanoparticle-treated cells. Note that enlarged lysosomes (No serum + nanoparticles) are normalized in cells pretreated with oleic acid (No serum + OA + nanoparticles). Nuclei and lysosomes were stained with Hoechst $33342(10 \mu \mathrm{M})$ and LysoTracker DND-99 (LTR) (500 nM), respectively, and images were acquired by fluorescent microscope. Scale bars, $20 \mu \mathrm{m}$. 
TGs are also utilized as fuel in starved cells exposed to nanoparticles.

The protection by oleic acid against nanoparticle-induced oxidative stress can be explained by multiple effects of oleic acid in living cells. For instance, aside from providing the fuel during starvation, oleic acid can also promote the activity of cellular antioxidant enzymes, such as superoxide dismutase and glutathione peroxidase. ${ }^{66,67}$ These two enzymes are part of the mitochondrial antioxidant system which promote mitochondrial integrity by scavenging free radicals. ${ }^{68}$ Nanoparticle cytotoxicity is largely mediated by the oxidation of lipids (lipid peroxidation) in subcellular membranes. ${ }^{13}$ Previous studies have shown that cells enriched in monounsaturated fatty acids (oleic acid), but not polyunsaturated fatty acids, were protected against oxidants, such as hydrogen peroxide and high oxygen (95\%), suggesting reduced lipid peroxidation in cells loaded with oleic acid. ${ }^{69,70}$ In our studies, oleic acid preconditioning prevented the enlargement of lysosomes in cells exposed to nanoparticles suggesting a beneficial effect of oleic acid on lysosomal integrity by indirectly reducing peroxidation of lysosomal membrane lipids. ${ }^{50}$

(39) Bampton, E. T.; Goemans, C. G.; Niranjan, D.; Mizushima, N.; Tolkovsky, A. M. The dynamics of autophagy visualized in live cells: from autophagosome formation to fusion with endo/ lysosomes. Autophagy 2005, 1 (1), 23-36.

(40) Gubern, A.; Barcelo-Torns, M.; Casas, J.; Barneda, D.; Masgrau, R.; Picatoste, F.; Balsinde, J.; Balboa, M. A.; Claro, E. Lipid droplet biogenesis induced by stress involves triacylglycerol synthesis that depends on group VIA phospholipase A2. J. Biol. Chem. 2009, 284 (9), 5697-708.

(41) Du, L.; Hickey, R. W.; Bayir, H.; Watkins, S. C.; Tyurin, V. A.; Guo, F.; Kochanek, P. M.; Jenkins, L. W.; Ren, J.; Gibson, G.; Chu, C. T.; Kagan, V. E.; Clark, R. S. Starving neurons show sex difference in autophagy. J. Biol. Chem. 2008, 284 (4), 2383 96.

(42) Goodrum, J. F.; Earnhardt, T. S.; Goines, N. D.; Bouldin, T. W. Lipid droplets in Schwann cells during tellurium neuropathy are derived from newly synthesized lipid. J. Neurochem. 1990, 55 (6), 1928-32.

(43) de Estable-Puig, R. F.; Estable-Puig, J. F. Intraneuronal lipid droplets in irradiated nervous tissue. Virchows Arch. B 1973, 14 (2), 117-25.

(44) Delikatny, E. J.; Cooper, W. A.; Brammah, S.; Sathasivam, N.; Rideout, D. C. Nuclear magnetic resonance-visible lipids induced by cationic lipophilic chemotherapeutic agents are accompanied by increased lipid droplet formation and damaged mitochondria. Cancer Res. 2002, 62 (5), 1394-400.

(45) Witt, S. N.; Flower, T. R. alpha-Synuclein, oxidative stress and apoptosis from the perspective of a yeast model of Parkinson's disease. FEMS Yeast Res. 2006, 6 (8), 1107-16.

(46) Zoula, S.; Rijken, P. F.; Peters, J. P.; Farion, R.; Van der Sanden, B. P.; Van der Kogel, A. J.; Decorps, M.; Remy, C. Pimonidazole binding in C6 rat brain glioma: relation with lipid droplet detection. Br. J. Cancer 2003, 88 (9), 1439-44.

(47) Vickers, A. E.; Bentley, P.; Fisher, R. L. Consequences of mitochondrial injury induced by pharmaceutical fatty acid oxidation inhibitors is characterized in human and rat liver slices. Toxicol. in Vitro 2006, 20 (7), 1173-82.

\section{Conclusion}

Results from these studies implicate that at least two different mechanisms could contribute to cell rescue and organelle adaptation by oleic acid in PC12 cells during starvation and nanoparticle-induced oxidative stress: (i) oleic acid-induced LDs serve as energy stores which at least in part prevent massive metabolic catastrophe in starved cells; (ii) oleic acid contributes to maintenance of lysosomal membrane integrity during a disturbance of the cellular redox balance initiated by CdTe nanoparticles.

In conclusion, our studies suggest that oleic acid priming and formation of lipid droplets could play a protective role in cells deprived from trophic factors and exposed to certain metallic nanoparticles and also likely to other nanomaterials disrupting homeostatic cellular redox balance.

Acknowledgment. We thank Ms. Jacynthe Laliberté for her assistance with the confocal microscope. We are grateful to Cory Glowinsky and to the McGill Life Sciences Complex Imaging Facility staff for their technical assistance with the 3D isosurface reconstruction and for their precious advice. We thank Alexandre Moquin for the synthesis and

(48) Hashimoto, T.; Fujita, T.; Usuda, N.; Cook, W.; Qi, C.; Peters, J. M.; Gonzalez, F. J.; Yeldandi, A. V.; Rao, M. S.; Reddy, J. K. Peroxisomal and mitochondrial fatty acid beta-oxidation in mice nullizygous for both peroxisome proliferator-activated receptor alpha and peroxisomal fatty acyl-CoA oxidase. Genotype correlation with fatty liver phenotype. J. Biol. Chem. 1999, 274 (27), 19228-36.

(49) Levine, B.; Yuan, J. Autophagy in cell death: an innocent convict. J. Clin. Invest. 2005, 115 (10), 2679-88.

(50) Kurz, T.; Terman, A.; Gustafsson, B.; Brunk, U. T. Lysosomes in iron metabolism, ageing and apoptosis. Histochem. Cell Biol. 2008, 129 (4), 389-406.

(51) Guillon-Munos, A.; van Bemmelen, M. X.; Clarke, P. G. Role of phosphoinositide 3-kinase in the autophagic death of serumdeprived PC12 cells. Apoptosis 2005, 10 (5), 1031-41.

(52) Isahara, K.; Ohsawa, Y.; Kanamori, S.; Shibata, M.; Waguri, S.; Sato, N.; Gotow, T.; Watanabe, T.; Momoi, T.; Urase, K.; Kominami, E.; Uchiyama, Y. Regulation of a novel pathway for cell death by lysosomal aspartic and cysteine proteinases. $\mathrm{Neu}$ roscience 1999, 91 (1), 233-49.

(53) Shibata, M.; Kanamori, S.; Isahara, K.; Ohsawa, Y.; Konishi, A.; Kametaka, S.; Watanabe, T.; Ebisu, S.; Ishido, K.; Kominami, E.; Uchiyama, Y. Participation of cathepsins B and D in apoptosis of PC12 cells following serum deprivation. Biochem. Biophys. Res. Commun. 1998, 251 (1), 199-203.

(54) Rubinsztein, D. C.; Gestwicki, J. E.; Murphy, L. O.; Klionsky, D. J. Potential therapeutic applications of autophagy. Nat. Rev. Drug Discovery 2007, 6 (4), 304-12.

(55) Uchiyama, Y. Autophagic cell death and its execution by lysosomal cathepsins. Arch. Histol. Cytol. 2001, 64 (3), 233-46.

(56) Shacka, J. J.; Roth, K. A.; Zhang, J. The autophagy-lysosomal degradation pathway: role in neurodegenerative disease and therapy. Front. Biosci. 2008, 13, 718-36.

(57) Ono, K.; Kim, S. O.; Han, J. Susceptibility of lysosomes to rupture is a determinant for plasma membrane disruption in tumor necrosis factor alpha-induced cell death. Mol. Cell. Biol. 2003, 23 (2), 66576.

(58) Kroemer, G.; Jaattela, M. Lysosomes and autophagy in cell death control. Nat. Rev. Cancer 2005, 5 (11), 886-97. 
characterization of CdTe nanoparticles, and H. Vali and J. Mui for technical assistance in electron microscopy. A.K. is supported by the McGill Graduate Studies Fellowship. D.M. is supported by Canadian Institutes for Health Research (CIHR) and National Science and Research Council (NSERC, Canada).

Supporting Information Available: Examination of colocalization between lipid droplets and lysosomes in PC12 treated with oleic acid and CdTe nanoparticles for $24 \mathrm{~h}$. Pictures and

(59) Cutler, R. G.; Kelly, J.; Storie, K.; Pedersen, W. A.; Tammara, A.; Hatanpaa, K.; Troncoso, J. C.; Mattson, M. P. Involvement of oxidative stress-induced abnormalities in ceramide and cholesterol metabolism in brain aging and Alzheimer's disease. Proc. Natl. Acad. Sci. U.S.A. 2004, 101 (7), 2070-5.

(60) Furukawa, S.; Fujita, T.; Shimabukuro, M.; Iwaki, M.; Yamada, Y.; Nakajima, Y.; Nakayama, O.; Makishima, M.; Matsuda, M.; Shimomura, I. Increased oxidative stress in obesity and its impact on metabolic syndrome. J. Clin. Invest. 2004, 114 (12), 1752 61.

(61) Liu, P.; Ying, Y.; Zhao, Y.; Mundy, D. I.; Zhu, M.; Anderson, R. G. Chinese hamster ovary K2 cell lipid droplets appear to be metabolic organelles involved in membrane traffic. J. Biol. Chem. 2004, 279 (5), 3787-92.

(62) Melo, R. C.; Fabrino, D. L.; Dias, F. F.; Parreira, G. G. Lipid bodies: Structural markers of inflammatory macrophages in innate immunity. Inflammation Res. 2006, 55 (8), 342-8.

(63) Listenberger, L. L.; Ory, D. S.; Schaffer, J. E. Palmitate-induced apoptosis can occur through a ceramide-independent pathway. J. Biol. Chem. 2001, 276 (18), 14890-5.

(64) Chai, W.; Liu, Z. p38 mitogen-activated protein kinase mediates palmitate-induced apoptosis but not inhibitor of nuclear factorkappaB degradation in human coronary artery endothelial cells. Endocrinology 2007, 148 (4), 1622-8. a movie file (.avi) of 3D image isosurface reconstruction of lipid droplets found within lysosomes using the 3D image analysis software Imaris (Bitplane). Assessment of cell viability upon CdTe nanoparticle treatment in cells cultured in serum-containing media, and effect of oleic acid or palmitic acid-priming. This material is available free of charge via the Internet at http://pubs.acs.org.

MP900098P

(65) Listenberger, L. L.; Han, X.; Lewis, S. E.; Cases, S.; Farese, R. V., Jr.; Ory, D. S.; Schaffer, J. E. Triglyceride accumulation protects against fatty acid-induced lipotoxicity. Proc. Natl. Acad. Sci. U.S.A. 2003, 100 (6), 3077-82.

(66) Duval, C.; Auge, N.; Frisach, M. F.; Casteilla, L.; Salvayre, R.; Negre-Salvayre, A. Mitochondrial oxidative stress is modulated by oleic acid via an epidermal growth factor receptor-dependent activation of glutathione peroxidase. Biochem. J. 2002, 367 (Part 3), 889-94.

(67) Xu, Q. M.; Cheng, J. S.; Ge, Z. Q.; Yuan, Y. J. Antioxidant responses to oleic acid in two-liquid-phase suspension cultures of Taxus cuspidata. Appl. Biochem. Biotechnol. 2005, 125 (1), $11-26$.

(68) Moldovan, L.; Moldovan, N. I. Oxygen free radicals and redox biology of organelles. Histochem. Cell Biol. 2004, 122 (4), 395412.

(69) Spitz, D. R.; Kinter, M. T.; Kehrer, J. P.; Roberts, R. J. The effect of monosaturated and polyunsaturated fatty acids on oxygen toxicity in cultured cells. Pediatr. Res. 1992, 32 (3), 366-72.

(70) Hart, C. M.; Gupta, M. P.; Evanoff, V. Oleic acid reduces oxidant stress in cultured pulmonary artery endothelial cells. Exp. Lung Res. 1997, 23 (5), 405-25. 